\title{
A Ordem Jurídica no Discurso da Servidão Voluntária
}

\author{
Eliardo França Teles Filho ${ }^{\mathrm{I}-}$ (100000-0003-1667-5689 \\ Faculdade de Direito da Universidade de São Paulo, São Paulo, SP, Brasil
}

Resumo: O artigo busca mostrar que O Discurso da Servidão Voluntária contém uma defesa da liberdade contra a tirania, mas dentro de um quadro implícito de ordem e de paz, no qual uma concepção do direito garante a liberdade.

Palavras-chave: Étienne de la Boétie, liberdade, ordem, direito natural, paz.

\section{El orden jurídico en el Discurso de la servidumbre voluntaria de Étienne de la Boétie}

Resumén: El artículo busca mostrar que el Discurso de la Servidumbre Voluntaria contiene una defensa de la liberdad contra la tiranía, más dentro de un ordenamiento jurídico (aunque implícito) ancorado en una concepción jusnaturalista del derecho, la cual garantiza la libertad.

Palavras-clave: Étienne de la Boétie, libertad, orden, ley natural, paz.

\section{The legal order on the Discourse on voluntary servitude of Étienne de la Boétié}

\footnotetext{
Abstract: This paper aims at showing that the Discourse on Voluntary Servitude contains a defense of liberty against tyrany, but the struggle for liberty is to be carried out within a legal order that stemms from a natural lawyer point of view.
}

Keywords: Étienne de la Boétie, freedom, order, natural law, peace.

\footnotetext{
IAdvogado, assessor jurídico na Câmara dos Deputados, doutorando em Direito Constitucional na Universidade de São Paulo. Mestre em Direito pelo Centro Universitário de Brasília - UniCeub. Marie Curie Fellow na École des Hautes Études em Sciences Sociales de Paris - EHESS e na London School of Economics and Political Sciences - LSE, nos anos de 2006 a 2009. E-mail: eliardofteles@gmail.com
} 


\section{Introdução}

O Discurso da Servidão Voluntária fascina leitores de vários campos ideológicos há séculos. Um dos primeiros a se encantar com a obra foi Montaigne (1595) ${ }^{1}$, que estabeleceu relação de profunda amizade com o autor do Discurso, Étienne de la Boétie ${ }^{2}$. Depois, o texto foi publicado por editores huguenotes ${ }^{3}$, e para o desgosto de Montaigne (1595, s/p.), foi republicado por "um comunista", "na língua militante do século XIX" (ABENSOUR; GAUCHET, 2008, p. 9), e apropriado por pensadores identificados com a esquerda (NEWMAN, 2011, p. 23-48) e com a direita (ROTHBARD, 2012). Isso quer dizer que o Discurso permite uma multiplicidade de leituras e apropriações (ABENSOUR; GAUCHET, 2008, p. 9), tornando difícil para o leitor fixar seu autor, numa esfera ideológica específica.

Alguns de seus leitores entenderam que "a lição fundamental [do Discurso] é que o poder não depende da coerção, mas, na realidade, se apoia no nosso poder" (NEWMAN, 2011, p. 20-24). Outros veem no Discurso, uma especulação "sobre a natureza não apenas da tirania, mas também implicitamente da natureza do próprio aparato do estado" (ROTHBARD, 2012). Tolstoy se concentra no valor da verdade versus a mentira, afirmando que La Boétie desvelou a origem da mentira que permite que poucos logrem a oprimir muitos, contrariamente à intuição, que suporia que a dominação é dos mais fortes sobre os mais fracos. O que parece atrair o grande escritor russo é a descrição de uma servidão, que não tem necessidade do uso da força, que não tem necessidade de que um grande número de fato force os oprimidos a consentirem com sua opressão, em resumo, o aspecto pacífico do consentimento à servidão ${ }^{4}$.

Esses aspectos, no entanto, têm sido suficientemente abordados pela literatura, tanto a militante quanto a acadêmica. Porém, um aspecto, interessante do ponto de vista da filosofia

\footnotetext{
${ }^{1}$ Montaigne escreveu antes de 1595 (s/p.): "J'avais projeté de placer ici son «Discours sur la servitude volontaire»; mais depuis, cet écrit a déjà vu le jour". Tradução livre: "Eu havia pensado publicar, aqui, seu Discurso da Servidão Voluntária, mas de lá para cá, esse texto já foi publicado".

${ }^{2}$ Montaigne publicou uma homenagem a Étienne de la Boétie, chamada "De l'amitité", ou Da Amizade. O texto está no Livro I, dos Ensaios de Montaigne. Disponível em: https://www.gutenberg.org/files/48529/48529h/48529-h.htm. Acesso em: 17 dez 2019.

${ }^{3}$ Segundo afirma Murray Rothbard (2012): “Ele foi publicado pela primeira vez, embora anonimamente e incompleto, no panfleto radical huguenote Reveille-Matin des Francois (1574), escrito talvez por Nicholas Barnaud com a colaboração de Theodore Beza".

4 "We can see that governments insist that good order cannot be maintained without violence, really meaning by the word "order" the maintenance of a government that permits a minority to profit as much as it likes by the work of the majority. We can see why they say it, for the suppression of violence would take away their means of continuing their present existence and would denounce its iniquity of long standing. This ought not to be the case for the mass of workers who employ violence on each other and who suffer from it so cruelly. The situation of the oppressed should not be compared to the constraint used directly by the stronger on the weaker, or by a greater number on a smaller number. Here, indeed, it is the minority that oppresses the majority, thanks to a lie established ages ago by clever people, in virtue of which men despoil each other, for insignificant profits, of much greater advantages - such as liberty - and are exposed to painful suffering" (TOLSTOY, 1948, p. 14 [grifos feitos por este autor]).
} 
política e do direito, é pouco abordado. Trata-se da questão de saber a relação de La Boétie com o direito, principalmente o direito natural. Se, de um lado, há toda uma tradição que parece querer situar o autor como um libertário ou um anarquista, seu amigo Montaigne afirmava, como se fizesse uma defesa de La Boétie, que:

Eu não coloco em dúvida que La Boétie pensava aquilo que escrevia, pois ele era demasiado consciencioso para mentir, mesmo de brincadeira; e eu sei que ele teria preferido, o que eu compreendo, ter nascido em Veneza que em Sarlat; mas obedecer e se submeter escrupulosamente às leis sob as quais ele vivia, era outro princípio que, para ele, se sobrepunha a tudo. Nunca houve melhor cidadão; ninguém desejou tanto a tranquilidade para seu país, nem foi mais inimigo das agitações e das ideias novas que se produzem no nosso tempo. (MONTAIGNE, 1906, s/p. [tradução livre])

Trata-se, claro, de uma observação sobre o caráter de La Boétie, mais do que sobre seu pensamento. Contudo, essa espécie de defesa feita por Montaigne, permite-nos levantar a hipótese de que o autor do Discurso trabalhava sobre uma concepção de ordem jurídica que permanece implícita, ou é mencionada de passagem ao longo do texto. Em outras palavras, pretendemos defender, a partir do texto de La Boétie, que é possível que houvesse alguma ideia de ordem jurídica ancorando a tese de que todo governo pode cair sem o uso da força, desde que os cidadãos retirem o poder que lhe conferem voluntariamente.

Para sustentar a afirmação de que La Boétie pode ser visto como um crente, ainda que não sectário, da existência de ordem na sociedade, defenderemos que 1) o Discurso é sobretudo contra a tirania, embora seus insights possam servir de ferramenta para se pensar qualquer forma de governo e poder; 2) a grande novidade do Discurso não é tanto defender que o povo pode se revoltar contra seu governo, mas, como defendia Tolstoy (1948), afirmar que o governo pode perder seu poder desde que o povo, pacificamente, o queira; e 3) que La Boétie acreditava na ordem do direito natural, ou, pelo menos, numa ordem da natureza.

\section{O Discurso contra a tirania}

Uma das intuições mais fecundas do Discurso é a que mostra que existe um tipo de ligação subjetiva, e de poder, entre o governante e sujeitos ${ }^{5}$. Essa ideia, por si só, já seria suficiente para garantir, ao seu autor, um lugar entre os pensadores pós-estruturalistas, como Michel Foucault. Como se sabe, uma das ideias defendidas por Foucault mostrava que o sujeito era

\footnotetext{
${ }^{5}$ Saul Newman (2011, p. 24) afirma: “La Boétie observa o vínculo subjetivo que nos amarra ao poder, que nos domina, encanta e seduz, cega e hipnotiza. A lição fundamental é que o poder não depende da coerção, mas, na realidade, se apóia no nosso poder. É o nosso consentimento ativo ao poder que constitui, ao mesmo tempo, esse poder".
} 
constituído pelo poder ${ }^{6}$, ao mesmo tempo em que constituía ele mesmo o poder ${ }^{7}$. Ou seja, haveria uma forma de ligação subjetiva entre o sujeito e o poder.

Sem querer ir longe demais, e defender que La Boétie e Foucault estavam dizendo a mesma coisa, queremos apenas comparar os dois textos para mostrar como o insight do Discurso é atual, contemporâneo, ao mostrar essa relação de mão dupla, entre o sujeito e o poder. Nesse sentido, o Discurso pode ser interpretado, de fato, como uma análise do poder político e do governo em geral.

Queremos aqui explorar outra possibilidade do texto do Discurso, que não invalida e, aliás, nem compete com a primeira: a de que o Discurso centrava suas forças principalmente nas tiranias, ou no consentimento dos sujeitos, o qual era o sustentáculo das tiranias. A razão de insistirmos nesse sentido do Discurso, aqui, não é a interpretação em si, mas seu lugar na construção da hipótese de que La Boétie ancorava sua interpretação em uma ideia de ordem jurídica (que é o tema central deste paper).

Um dos trechos mais célebres do Discurso começa com a seguinte frase:

Por hora gostaria apenas de entender como pode ser que tantos homens, tantos burgos, tantas cidades, tantas nações suportam às vezes um tirano só, que tem apenas o poderio que eles lhe dão, que não tem o poder de prejudicá-los senão enquanto têm vontade de suportá-lo, que não poderia fazer-lhes mal algum senão quando preferem tolerá-lo a contradizê-lo. (LA BOÉTIE, 2012 [grifos inseridos pelo autor])

Em outro trecho, ele dá a entender que existe uma hierarquia entre república e monarquia:

Se eu fosse debater, antes mesmo de procurar que lugar a monarquia deve ocupar entre os diversos modos de governar a coisa pública, eu quereria saber si deveríamos sequer reservar algum lugar à monarquia, haja vista que é bem difícil crer que haja algo de público nessa espécie de governo. (LA BOÉTIE, 1549, [traduzido pelo autor])

Portanto, para ele, o governo republicano deve ser pelo menos mais tolerável do que o monárquico, ou mais aceitável. Claro que isso não nos permite afirmar que a república para ele é um bom governo. Apenas que ele não considera todo governo como igualmente ruim e tirano. Essa opinião é corroborada por outro trecho, no qual ele afirma que o governante, que chega ao poder pelo povo, deveria ser mais suportável, ao menos, que é o que se esperaria, mas, logo depois, reconhece que, na prática, não é exatamente o que ocorre (LA BOÉTIE, 2012).

\footnotetext{
6 "Em outras palavras, ao invés de perguntar como o soberano aparece no topo, tentar saber como foram constituídos, pouco a pouco, progressivamente, realmente e materialmente, os súditos, a partir da multiplicidade de corpos, das forças, das energias, das matérias, dos desejos, dos pensamentos, etc. Captar a instância material da sujeição enquanto constituição dos sujeitos, precisamente o contrário do que Hobbes quis fazer no Leviatã e, no fundo, do que fazem os juristas..." (FOUCAULT, 1979, p. 183). Registramos que Saul Newman também afirma isso: "O problema da servidão voluntária é exatamente o oposto daquele levantado por Hobbes um século depois" (NEWMAN, 2011, p. 25).

7 “Nas suas malhas, os indivíduos não só circulam mas estão sempre em posição de exercer este poder e sofrer sua ação; nunca são o alvo inerte ou consentido do poder, mas são sempre centros de transmissão". (FOUCAULT, 1979, p. 183)
} 
Mas o Discurso vai mais longe. Ele nos dá elementos embrionários de uma definição de tirania, e explicita o que ele considera como seus fundamentos e seu modo de funcionamento. A definição embrionária de tirania está contida no seguinte trecho:

... os aldeões, os camponeses que espezinham o quanto podem e os tratam pior do que a forçados ou escravos - verão que esses, assim maltratados, são no entanto felizes e mais livres do que eles. O lavrador e o artesão, ainda que subjugados, ficam quites ao fazer o que lhes dizem; mas o tirano vê os outros que lhe são próximos trapaceando e mendigando seu favor; não só é preciso que façam o que diz mas que pensem o que quer e amiúde, para satisfazê-lo, que ainda antecipem seus pensamentos. Para eles não basta obedecê-lo, também é preciso agradá-lo, é preciso que se arrebentem, que se atormentem, que se matem de trabalhar nos negócios dele; e já que se aprazem com o prazer dele, que deixam seu gosto pelo dele, que forçam sua compleição, que despem o seu natural, é preciso que estejam atentos às palavras dele, à voz dele, aos sinais dele, e aos olhos dele; que não tenham olho, pé, mão, que tudo esteja alerta para espiar as vontades dele e descobrir seus pensamentos. Isso é viver feliz? Chama-se a isso, viver? (LA BOÉTIE, 2012 [grifos inseridos pelo autor])

Nesse trecho, um dos mais fortes do Discurso, La Boétie mostra a diferença entre obediência e submissão. A obediência, que La Boétie afirma ser o suficiente para que um trabalhador satisfaça o tirano, não o satisfaz, quando se trata de suas relações com aqueles cujo interesse garante a obediência dos outros. Aqui, é bom trazer o trecho em que La Boétie explica o funcionamento da tirania:

Grande é o séquito que vem depois e quem quiser divertir-se esvaziando essa rede não verá os seis mil mas os cem mil, os milhões que por essa corda agarram-se ao tirano servindose dela como Júpiter em Homero, que se gaba de trazer a si todos os deuses ao puxar a corrente. (LA BOÉTIE, ano, s/p.)

A figura da corrente mostra bem o mecanismo, dentro do qual se desenvolvem as relações entre o tirano e seus clientes/apoiadores. O poder vem dos apoiadores e vai para o tirano, que devolve poder para seus apoiadores, agora clientes, os quais ajudam-no a sustentar-se. Ao mesmo tempo, essa relação é de desconfiança e, portanto, opressora, tanto para os clientes do tirano, quanto para ele ${ }^{8}$.

Essa desconfiança se reflete na sociedade inteira, que deixa de ser uma sociedade e passa a ser chamada de "complô" ou de "conspiração". No texto em francês, La Boétie (1549, s/p. [tradução livre]), afirma o seguinte: "Entre maus, quando eles se reúnem, há uma conspiração, não uma sociedade" ${ }^{\prime \prime}$. Aqui, se mostra que, ao lado da hierarquia entre tipos de governo, La Boétie reconhece uma hierarquia de laços sociais e de formação de sociedade. À tirania,

\footnotetext{
${ }^{8}$ La Boétie lembra como muitos tiranos terminaram mortos por seus próprios apoiadores:

9 "Certainement le tyran n'aime jamais et jamais n'est aimé. L'amitié, c'est un nom sacré, c'est une chose sainte : elle ne peut exister qu'entre gens de bien, elle naît d'une mutuelle estime, et s'entretient non tant par les bienfaits que par bonne vie et mœurs. Ce qui rend un ami assuré de l'autre, c'est la connaissance de son intégrité. Il a, pour garants, son bon naturel, sa foi, sa constance ; il ne peut y avoir d'amitié où se trouvent la cruauté, la déloyauté, l'injustice. Entre méchants, lorsqu'ils s'assemblent, c'est un complot et non une société. Ils ne s'entretiennent pas, mais s'entrecraignent. Ils ne sont pas amis, mais complices" (LA BOÉTIE, 1549, p. 47).
} 
como a define embrionariamente o Discurso, correspondem, não laços positivos e nem mesmo uma sociedade, mas laços de adulação e opressão, e um conjunto de pessoas que não é uma sociedade, mas um complô.

Portanto, dentro do espaço permitido por esse paper, é possível identificar elementos, que permitem afirmar que o Discurso comporta, ao lado daquela interpretação mais avançada e até mais fecunda, uma outra: a de que La Boétie talvez não fosse contrário a todo e qualquer tipo de governo, mas principalmente à tirania, e a ela dirige sua crítica mais poderosa. Essa demonstração é um passo importante para a defesa da hipótese de que o autor constrói seu pensamento, sobre uma concepção de ordem jurídica.

\section{A revolução pacífica do Discurso}

Talvez menos controvertida seja a defesa da interpretação, de que La Boétie não é um teórico da revolução armada ou violenta. Essa ideia já se via refletida no texto De l'amitié, de seu amigo Montaigne (citado acima). O que deixava o autor do Discurso perplexo, não era o fato de que os sujeitos não pegassem em armas contra o tirano, mas, sim, que, uma vez que bastava renunciar ao apoio ao tirano para derrubá-lo, por que razão os sujeitos pareciam preferir tolerá-lo?

Um trecho do Discurso (2012) coloca essa ideia de forma bastante clara:

No entanto, não é preciso combater esse único tirano, não é preciso anulá-lo; ele se anula por si mesmo, contanto que o país não consinta a sua servidão; não se deve tirar-lhe coisa alguma, e sim nada lhe dar; não é preciso que o país se esforce a fazer algo para si, contanto que nada faça contra si.

Claro que não se extrai, do Discurso, que La Boétie era um pacifista ou que fosse contra o recurso às armas contra a tirania. Se fôssemos apostar, o estilo inflamado do texto nos faria apostar no contrário. Mas é legítimo defender a interpretação de que o Discurso tem como um dos principais insights, se não o principal, o incômodo diante do fato de que, não é por não querer lutar, que os sujeitos sustentam uma tirania, mas simplesmente por não ignorarem-na, digamos. Portanto, o elemento da derrubada do tirano simplesmente parando de dar-lhe o poder que os sujeitos lhe dão.

Essa vertente da obra foi agarrada por Tolstoy, em seu texto, A Lei do Amor e a Lei da Violência. No texto, o escritor russo elabora um pensamento social que contraria o senso comum, muitas vezes abraçado por nós juristas: não é a violência que mantém unida a sociedade ${ }^{10}$. $E$, depois, constrói, sobre La Boétie, uma formulação lapidar, que poderia estar no Discurso: os

\footnotetext{
${ }^{10}$ Valemo-nos da expressão "senso comum abraçado por juristas", querendo lembrar, com isso, diversos usos que, são feitos da categoria da violência, principalmente na Teoria do Estado e na Teoria do Direito. Ali, ora a violência está na base do direito, como monopólio legítimo do Estado, ora está na base da sociedade, como ameaça contra a qual se institui a própria sociedade.
} 
trabalhadores poderiam recuperar sua liberdade mediante sua simples abstenção na prática da violência, que só é possível com sua cooperação (TOLSTOY, 1946, p. 15).

A violência, como fator de coesão social, é, para Tolstoy, a mentira que La Boétie desvela no Discurso. A razão pela qual os sujeitos pensam que, para derrubar um tirano, é necessário praticar atos violentos, é porque eles acreditam que o tirano só se mantém pela violência, quando, conforme o demonstrou La Boétie, o que mantém o tirano é a cooperação dos sujeitos na violência.

Assim, a revolta pacífica contra o tirano já é o suficiente para devolver a liberdade aos sujeitos. Essa ideia-força mostra que é possível extrair do texto que La Boétie não achava necessário revirar a sociedade, convulsioná-la, refazê-la por meio de engenharias sociais, para livrá-la do tirano. Bastaria a recusa em participar da violência, para que a liberdade lhes fosse devolvida.

\section{A ordem no Discurso}

Aqui, está a principal, e mais difícil, questão para a nossa hipótese: uma concepção de ordem perpassa todo o Discurso, embora situada no fundo do palco. Claro que não estamos afirmando que La Boétie fosse um defensor da ordem, nem um teórico da obediência. Mas apenas que ele acreditava em alguma ordem, dentro da qual a liberdade pudesse existir.

Um dos trechos que revela isso é o seguinte:

Em primeiro lugar creio não haver dúvida de que, se vivêssemos com os direitos que a natureza nos deu e com as lições que nos ensina, seriamos naturalmente obedientes aos pais, sujeitos à razão e servos de ninguém. Da obediência que cada um, sem outra advertência que a de sua natureza, presta a seus pai e mãe todos os homens testemunham, cada um por si. Da razão que nasce conosco ou não, o que é uma questão debatida a fundo pelos acadêmicos e abordada por toda a escola dos filósofos, por ora não pensaria falhar ao dizer o seguinte: há em nossa alma alguma semente natural de razão que, mantida por bom conselho e costume, floresce em virtude e, ao contrário, frequentemente sufocada, aborta, não podendo enfrentar os vícios sobrevindos. Mas, por certo se há algo claro e notório na natureza, e ao qual não se pode ser cego é que a natureza, ministra de deus e governante dos homens, fez-nos todos da mesma forma e, ao que parece, na mesma fôrma, para que nos entreconhecêssemos todos como companheiros, ou melhor, como irmãos. (LA BOÉTIE, 2012, s/p. [grifos inseridos pelo autor])

Fica claro que La Boétie acreditava que uma ordem podia ser boa, ainda que, talvez, fosse ideal. Pregando a natureza, o direito natural, a obediência aos pais, a educação da razão pelos costumes e pelos mesmos pais, o autor do Discurso não poderia estar defendendo a ausência de ordem, a anomia, o estado de completa anarquia.

Em outro trecho, o Discurso parece defender a ligação entre liberdade e natureza, fazendo derivar da natureza, também, a vontade de defender aquela liberdade: “Que a liberdade é natural, e que, na minha opinião, não somente nós nascemos com nossa liberdade, mas também com a vontade de defendê-la" (2012, p. 20). 
E a expressão "direito natural" também aparece no Discurso, como um fundamento para a própria organização de caráter do homem que não se deixa sujeitar e guarda em si aquela vontade de reivindicar seus direitos naturais:

... que não se submetem jamais à sujeição et que, sempre e sem cessar (assim como Ulysses procurando, por terra e mar, a rever a fumaça que saía da sua casa), nem esquecem seus direitos naturais e se apressam a reivindicá-los em todas as ocasiões. (LA BOÉTIE, 2012, p. 28).

Portanto, existe uma concepção de ordem, fundada no direito natural, que o sujeito, quando tem sua razão bem organizada pela obediência aos pais e pelos costumes, não hesita em defender. É dentro dessa ordem, que é jurídica, natural, racional, que florescem os indivíduos (agora, sim, o termo indivíduo cabe melhor que sujeito). E os indivíduos devem abster-se de cooperar com a violência do tirano, mas não devem abrir mão de defender essa dita ordem natural, donde emanam seus direitos naturais.

Claramente estamos diante de um autor que acreditava no jusnaturalismo. Contudo, não parece ainda um jusnaturalismo, que já havia se desprendido da ideia de uma ordem universal estabelecida por Deus. É o próprio La Boétie quem faz a ligação:

Para mim, eu penso com segurança e não creio me enganar, que, já que nada é mais contrário a Deus, soberanamente justo e bom, que a tirania; ele reserva, sem dúvida, um castigo terrível para os tiranos e seus cúmplices, bem no fundo do inferno. (LA BOÉTIE, 1549, p. 49 [traduzido pelo autor])

Essa concepção de direito natural, ainda emanando da ordem divina, talvez se encontrasse já na transição, entre o direito divino de Santo Agostinho ${ }^{11}$, e o direito natural, que viria a ser defendido pelos contratualistas. Se Agostinho defendia a existência de uma ordem divina, ele não defendia que a recusa à obediência ao tirano fosse um sinal da obediência à ordem de Deus. E os contratualistas, já situando na razão o fundamento da ordem natural, o faziam quase sempre para justificar a cessão de parte da liberdade original ao Estado.

\footnotetext{
${ }^{11} \mathrm{O}$ próprio Santo Agostinho tem uma obra difícil de classificar, e igualmente difícil de revelar uma teoria do direito. Daí a possibilidade de que ora autores vejam nele um defensor do jusnaturalismo quase tomista, ora um defensor do juspositivismo avant la lettre. Adotamos aqui, o posicionamento de Michel Viley (2006, p. 114 [traduzido pelo autor]): “Infinitamente vasta é a ideia de Lei Eterna. E, desse ponto de vista, já não existe contradição no fato de Santo Agostinho apreciar as leis do Estado, com um respeito que pressagia o positivismo jurídico, mas ao mesmo tempo lhas prefere um outro sistema jurídico, o direito sacro que a Idade Média tentaria realizar". Já Olivier Beaud, comentando a obra de Carl Schmitt, que ele qualifica de "augustinismo jurídico", enxerga uma ligação mais concreta entre o direito positivo e o direito divino, nessa vertente derivada do pensamento de Santo Agostinho (BEAUD, 2013, p. 50 e 52 [traduzido pelo autor]): “Como o próprio do augustinismo jurídico é de dar ao direito positivo uma grande autonomia em relação ao direito natural, que é visto como o delimitando, a gente compreende então por que o jovem Schmitt faz desde logo a apologia do voluntarismo o mais abrupto - a teoria da decisão - , e defende a autonomia do direito em face das ciências sociais - psicologia e sociologia - da filosofia ou da teologia. (...) Entretanto, o direito natural parece indispensável para unir as duas Cidades e renovar a ligação entre a ordem divina e a ordem celeste".
} 
La Boétie enxergava a ordem natural, justamente, no indivíduo que conservava a saudável postura de querer defender sua liberdade. Era o indivíduo que, com sua razão bem orientada pelos ensinamentos dos pais e dos costumes, agia, neste mundo, movido pela vontade de defender sua liberdade e, assim, realizava a ordem natural, vinda de Deus.

Talvez, essa ordem natural e esse indivíduo nela constituído sejam a chave para se interpretar a hierarquia, que La Boétie parece estabelecer entre a monarquia e a república, como formas de governar a coisa pública. E talvez, a recusa da violência como força de união entre as pessoas, formando uma sociedade, também fosse outro elemento dessa ideia mais ampla de uma ordem natural guiando diretamente as ações dos indivíduos e mostrando a eles quando era necessário resistir pacificamente à ordem mundana, quando ela começasse a tomar as formas de ação da tirania.

Acreditamos que esse encadeamento de ideias, cuja possibilidade apenas defendemos aqui, pode servir para organizar alguns outros tipos de pensamento, a partir do texto do Discurso, mostrando ali alguns elementos já com certa concretude jurídica. Mas isso, sem perder de vista que, o que fascina no Discurso, além do estilo interpelador, que parece estar dialogando diretamente com o leitor, é a abertura do texto a um diálogo interpretativo, que torna sua leitura um verdadeiro diálogo, entre o jovem huguenote francês de 19 anos e leitores de todas as épocas.

\section{Referências}

ABENSOUR, Miguel ; GAUCHET, Marcel. Présentation. Las lecciones de la servidumbre y su destino. In: El Discurso de la Servidumbre Voluntaria. La Plata: Terramar, 2008.

BEAUD, Olivier. Préface. Carl Schmitt ou le juriste engagé. In: SCHMITT, Carl. Théorie de la Constitution. Paris: Quadrige, 2013.

FOUCAULT, Michel. Soberania e disciplina. Curso do Collège de France, 14 de janeiro de 1976. In: Microfísica do Poder. Rio de Janeiro, 2004 [1979].

LA BOÉTIE, Étienne de. Le Discours de la Servitude Volontaire ou Le Contr'un. Transcrit par Charles Teste. 1549 [transcrição em francês moderno feita no Século XIX]. Disponível em: http://classiques.uqac.ca/classiques/ la_boetie_etienne_de/discours_de_la_servitude/discours_servitude_volontaire.pdf. Acesso em: 17 dez 2019.

LA BOÉTIE, Étienne de. O Discurso da Servidão Voluntária. São Paulo: Instituto Ludwig Von Mises Brasil, 2012. Tradução em português do Instituto Mises Brasil. Disponível em: https://mises.org.br/EbookChapter. aspx?id=445. Acesso em: 17 dez 2019.

MONTAIGNE, Michel de. Essais. Libre I. In: Gutenberg Project. Paris, 1906 [1595]. Disponível em: https://www. gutenberg.org/files/48529/48529-h/48529-h.htm. Acesso em: 17 dez 2019.

NEWMAN, Saul. A servidão voluntária revisitada: a política radical e o problema da auto-dominação. Revista Verve: Revista Semestral Autogestionária do Nu-Sol (Núcleo de Sociabilidade Libertária do Programa de Estudos Pós-Graduados em Ciências Sociais da PUC-SP), n. 20, p. 23-48, 2011.

ROTHBARD, Murray. O pensamento político de Étienne de La Boétie. São Paulo: Instituto Ludwig Von Mises Brasil, 2012. Disponível em: https://www.mises.org.br/EbookChapter.aspx?id=446. Acesso em: 17 dez 2019. 
TOLSTOY, Leon. The Law of Love and the law of violence. Nova Iorque: Rudolph Field, 1948. Disponível em: http://www.nonresistance.org/docs_pdf/Tolstoy/Law_of_Love.pdf. Acesso em: 17 dez 2019.

VILEY, Michel. La formation de la pensée juridique moderne. Paris: Quadrige, 2006. 